\title{
The electrocardiogram change of conus branch occlusion during right coronary artery angioplasty
}

\author{
Toshiki Kuno, Taishi Fujisawa, Yohei Numasawa, Toshiyuki Takahashi \\ Department of Cardiology, Ashikaga Red Cross Hospital, Tochigi, Japan \\ Correspondence: Toshiki Kuno. Address: Department of Cardiology, Ashikaga Red Cross Hospital 284-1 Yobe-cho, \\ Ashikaga-shi, Tochigi, Japan. Email: kuno-toshiki@hotmail.co.jp
}

Received: December 2, 2014

Accepted: December 29, 2014 Online Published: January 14, 2015

DOI : $10.5430 /$ crim.v2n2p7

URL: http://dx.doi.org/10.5430/crim.v2n2p7

\begin{abstract}
There are few reports of electrocardiogram (ECG) changes of conus branch occlusion. A conus branch artery supply to the outflow tract of right ventricle. A conus branch artery is considered as the substrate of Brugada syndrome. We report a case of conus branch occlusion during angioplasty with ST segment elevation in $\mathrm{V}_{1-3}$ like Brugada syndrome ECG. We need to bear in mind that this ECG change may cause lethal arrhythmia.
\end{abstract}

\section{Keywords}

Conus branch occlusion, Brugada syndrome, Electrocardiogram change

\section{I ntroduction}

A conus branch artery supply to the outflow tract of right ventricle. A conus branch artery is considered as the substrate of Brugada syndrome. After conus branch occlusion during angioplasty, anterior ST segment elevation was detected in the previous reports ${ }^{[1-5]}$. However, some of these electrocardiogram (ECG) changes were not typical type of Brugada syndrome. We report a case of conus branch occlusion during angioplasty with ST segment elevation in $\mathrm{V}_{1-3}$ like Brugada syndrome ECG.

\section{Case report}

A 80 year old female presented to the outpatient clinic with chest pain while walking for a month. She was scheduled to undergo coronary angiography because of suspicion of angina. She underwent coronary angiography which revealed $99 \%$ stenosis of the mid right coronary artery (RCA) and 90\% stenosis of ostium of RCA (Figure 1a, an arrow= conus branch). Therefore, we performed percutaneous coronary intervention with implantation of stents in the mid RCA and proximal RCA. After implanting the stent in the proximal RCA, she complained of chest pain. Angiography showed occlusion of the conus branch (Figure 1b, an arrow). Her electrocardiogram showed ST elevation in $\mathrm{V}_{1-3}$ like Brugada syndrome (Figure 2a, arrows) compared to the previous one (Figure 2b). However, without intervention, her symptom had disappeared within several minutes and electrocardiogram had been normalized. Although there was no evidence of the recanalization of the conus branch artery at that time, we might suspect that no flow of the conus branch artery was due to plaque shift or distal emobolization, and we might expect microcirculation would restore because of the resolution of the 
ECG change and chest pain. Cardiac enzymes were not elevated after the procedure. She was followed up for 12 months without chest pain. Follow-up coronary angiography showed recanalization of the conus branch artery fortunately.

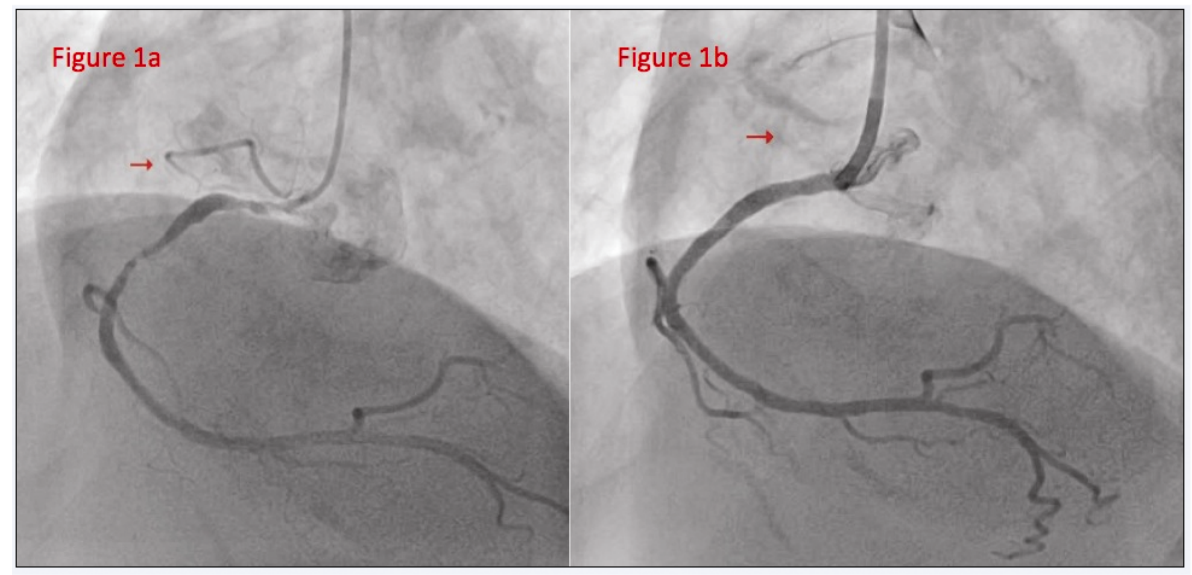

Figure 1a. It showed coronary angiography of the RCA before PCI. An arrow was a conus branch. Figure 1b. It showed coronary angiography of the RCA after PCI. An arrow showed the occluded conus branch.

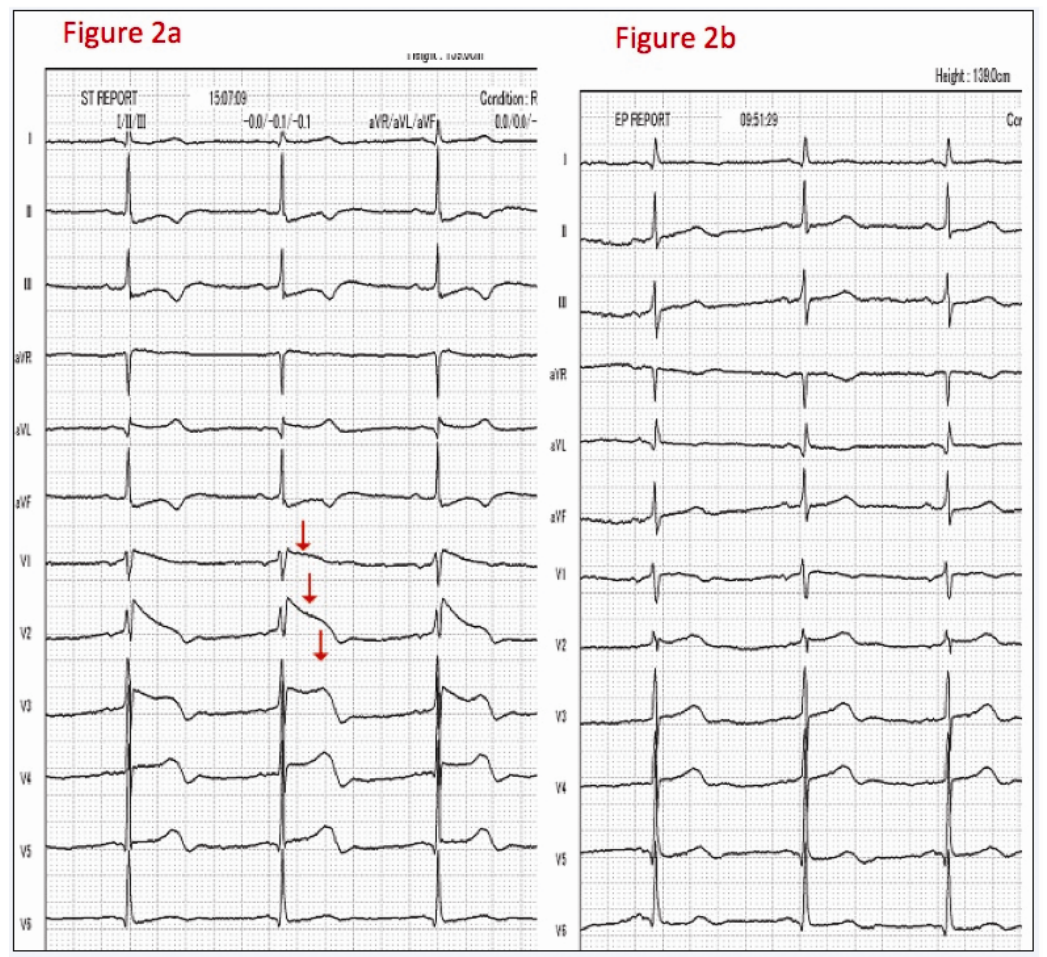

Figure 2a. It showed ECG after PCI. Arrows showed ST elevation in $\mathrm{V}_{1-3}$ leads like Brugada syndrome. Figure 2b. It showed ECG before PCI. There was no ST elevation in $\mathrm{V}_{1-3}$. (Abbreviation; RCA, right coronary artery, PCI, percutaneous coronary intervention, ECG, electrocardiogram)

\section{Discussion}

This case report showed a dramatic ECG change after the conus branch occlusion. ECG change was similar to Brugada syndrome ECG (coved type). It is well known that a conus branch artery supply to the outflow tract of right ventricle. 
Conus branch ischemia induced electrical depression in the ventricular epicardial action potential dome, transmural dispersion of the repolarization, and phase 2 reentry capable of precipitating ventricular tachycardia/fibrillation, and electrical depression in the epicardium might be the cause of ST elevation in $V_{1-3}{ }^{[3,6]}$. This mechanism is similar to that seen in patients with Brugada syndrome ${ }^{[3]}$. Therefore, a conus branch artery is considered as the substrate of Brugada syndrome and after acetylcholine infusion of the conus branch artery, ventricular tachycardia had occurred in the previous report and $10 \%$ of patients with Brugada syndrome were complicated with vasospasms of the conus branch artery because incidence rate was high in Asian people, and the autonomic nervous system plays an important role ${ }^{[7,8]}$. In this case, fortunately, the ECG change had been normalized within several minutes and no lethal arrhythmia happened, however we need to bear in mind that this ECG change may cause lethal arrhythmia.

\section{References}

[1] Eichhofer J, and N Curzen. Images in cardiovascular medicine. Unexpected profound transient anterior ST elevation after occlusion of the conus branch of the right coronary artery during angioplasty. Circulation. 2005; 111(9): e113-4. PMid:15753220 http://dx.doi.org/10.1161/01.CIR.0000157152.65623.23

[2] Celik T, et al. Precordial ST-segment elevation in acute occlusion of the proximal right coronary artery. J Electrocardiol. 2006; 39(3): 301-4. PMid:16777516 http://dx.doi.org/10.1016/j.jelectrocard.2006.02.003

[3] Yamaki M, et al. Possible contribution of ischemia of the conus branch to induction or augmentation of Brugada type electrocardiographic changes in patients with coronary artery disease. Int Heart J. 2010; 51(1): 68-71. PMid:20145355 http://dx.doi.org/10.1536/ihj.51.68

[4] Hernandez Hernandez F, et al. Recurrent ventricular fibrillation and ST segment elevation in the right precordial leads due to acute occlusion of the conus branch. Rev Esp Cardiol. 2011; 64(12): 1226-7. PMid:21676521 http://dx.doi.org/10.1016/j.recesp.2011.02.017

[5] Umemura M, et al. Acute myocardial infarction with isolated conus branch occlusion. J Electrocardiol. 2012; 45 (3): 285-7. PMid:22217367 http://dx.doi.org/10.1016/j.jelectrocard.2011.11.006

[6] Di Diego, J M Fish, and C Antzelevitch. Brugada syndrome and ischemia-induced ST-segment elevation. Similarities and differences. J Electrocardiol. 2005; 38(4 Suppl): 14-7. PMid:16226068 http://dx.doi.org/10.1016/j.jelectrocard.2005.06.003

[7] Ogano M, et al. Proarrhythmic ECG deterioration caused by myocardial ischemia of the conus branch artery in patients with a Brugada ECG pattern. Pacing Clin Electrophysiol. 2011; 34(3): e26-9. PMid:20353416 http://dx.doi.org/10.1111/j.1540-8159.2010.02742.x

[8] Noda T, et al. ST-segment elevation and ventricular fibrillation without coronary spasm by intracoronary injection of acetylcholine and/or ergonovine maleate in patients with Brugada syndrome. J Am Coll Cardiol. 2002; 40(10): 1841-7. http://dx.doi.org/10.1016/S0735-1097(02)02494-4 